\title{
Lipases, Definition, and their Application
}

\author{
Waznah Moayd ${ }^{1,2}$ and Yunjun Yan ${ }^{1 *}$ \\ 1. Key Laboratory of Molecular Biophysics of the Ministry of Education, College of Life Science and \\ Technology, Huazhong University of Science and Technology, Wuhan, 430074, P. R. China \\ 2. Biology Department, College of Science, Taibah University, Madinah, Kingdom of Saudi Arabia
}

\begin{abstract}
Esterase and lipase have been consisted of $\alpha / \beta$ hydroxylase super family that characterized primarily by their $\alpha / \beta$ hydroxylase fold (common fold), which is in the center, pre-dominantly parallel $\beta$-sheet and flanked via the connections of $\alpha$-helical. Nucleophilic elbow is an esterases and lipases that shared the characteristic sequence motifs (GXSXG). The residues of these amino acids compose a triad of catalyse in the specific-order (serine - aspartic acid - histidine) in the chain of polypeptide. Consequently, the most of lipases and esterases resemble serine-proteases and lipases in hydrolytic mechanism. Esterases (EC 3.1.1.1), as well as lipases (EC 3.1.1.3) are the versatile classes of biocatalysts. Due to their region-, enatio-selectivity and high specificity. Esterases are those that can catalyze the hydrolysis of short-acyl-chain-lengthed triglycerides less than 10, whereas, lipases are catalysts that can hydrolyze long-acyl-chain-lengthed triglycerides more than 10. Lipases applications can widely produce from a bacterial and fungal production. Lipases applications and their biotechnology significant are presented in different field such as medical biotechnology, detergent industries, organic synthesis, biodiesel production, agrochemical industries, flavor industries, and food industries.
\end{abstract}

Keywords: Lipase; Definition; Properties; Applications.

\section{Lipase and Esterase Definition}

Estarase and lipase are cosisted of $\alpha / \beta$ hydroxylase super famliy that characterized primarily by their $\alpha / \beta$ hydroxylase fold (common fold), which is in the center, pre-dominantly parallel $\beta$-sheet and flanked via the connections of $\alpha$-helical. Nucleophilic elbow is esterases and lipases that shared the characteristic sequence motifs (GXSXG) [1,2]. This motif is embeded by serine, and the mediation of ester hydrolysis by attacking the nucleophilic of serine active on the substrate carbonyl in the system of a charge relay with other two residues of amino acid (histidine and aspartic acid) [1]. The residues of these amino acids compose a triad of catalyse in the specific-order (serine - aspartic acid - histidine) in the chain of polypeptide [3-6]. Forthat, the most of lipases and esterases resemble serine-proteases and lipases in hydrolytic mechanims. Esterases (EC 3.1.1.1), as well as lipases (EC 3.1.1.3)are the versatile classes of biocatalysts due to their region-, enatio-selectivity and high specificity. Esterases are those that can catalyze the hydrolysis of less than 10 short-acyl-chain-lengthed triglycerides, whereas, lipases are catalysts that can hydrolyze more than 10 long-acyl-chain-lengthed triglycerides. Studies of the structure displayed that the presene or absence of lid structure caused the diffrentiation between esterases and lipases and responsible for lipase interfacial activation [4-7]. Life kindoms has a widely distribution from esterase and lipases.

In a widly ranging from organisms, esterases and lipases have been identified and cloned severel of them. Acinetobacter [8, 9], Bacillus [10,11] and Pseudomonas [12,13] are examples from various microbial strains that possess identifing and cloning of esterases and lipases. The studies have been reported that, metal ions and organic solvent resistance related to microbial esterases and lipases [14]. Thus, they should be catalysis effeceintly in organic synthisis for an enantio- and regionselective reactions, among the groups biocatalysis that have been the most important in biotechnology. The optically pure substances in organic synthesis have been used esterases and lipases successfully.

\section{Lipase application}

Lipases applications can be widely produced from a bacterial and fungal production. In fact, they have stability in organic solvent wide range and many present high thermostabilities, they have optimal range of temperature and wider $\mathrm{pH}$ than eukaryotic origin lipases, and have a high diverse range of substrate with high enantio- and regioselectivity making an important microbial lipases and attractive choice in organic synthesis for many applications. Lipases from mesophilic-organisms occupy the industrial application vast majority, mainly because they were isolated,cloned, and characterized. Lipases applications and their biotechnology significant are presented below [15-21]. 


\subsection{Medical Biotechnology}

One from lipase application is a medical biotechnology. It is an increasing demand for the industry of nutraceuticals that could be a food consideration that provide health benefits or medical including the treatment or/and preventaion of disease such as the lipase immobilization from Pseudomonas sp. within a hallow fiber reactor walls was the linoleic acid changes and presenting in oil of corn into conjugated-linoleic-acid (CLA) that a nutraceutical has antiatherogenic and anticarcinogenic activities [22]. Recently, in industrialized world, on of top issues of healthy is obesity e.g. it is serious disease in medicine that affects adults over a quarter in U.S.A, and adolescents and children about $14 \%$ according America-Obesity-Association (AOA) (http://www.obesity.org/). Developing lipase inhibitors is one of the potential obesity treatment. Among anti-obesity drugs, the first inhibitor of lipase is Orlistat; it has been presented to decrease the weight of body by adsorption inhibiting (by 30\%) dietery fat ingestity and it was targeted as obesity treatment novel approach [23]. Etodolac, ketoprofen, and indomethacin are nonsteroidal-antiinflammatory-drugs (NSAIDs). Their efficacy upon therapy is often limited due to their permeability and poor aqueous solubility [24]. Esters of forming suger using lipase is efficiency in drug solubility enhancment, and is quite efficient in prodrugs preparation; for example, psychrophile Candida antarctica using lipase for catalyze glucose transesterification with vinyl-ester of etodolac, ketoprofen, and indomethacin.

\subsection{Detergent Industries}

In industry of detergent, lipase has estimated one thousand tons, and are added each year approximatly 13 billion detergents produced tons [25]. Novo Nordisk (industrial enzymes leading company) introduced several lipases as additives of detergent through other application of various industries. They have the first production of commercial thermophilic lipase (Lipolase) produced by Theromyces lanuginosis and used in the industry of detergent. Lipases from other bacteria as Lipomax produced by Pseudomonas alcaligenes and Lumfast produced by Pseudomonas mendocina were mesophilic production by Genencor-International and used like detergent additives [19]. In comparing to discovered enzymes recently, the present utilized enzymes are not the highest thermostable, efficient, or lipases resistant detergent. Apparently, the production process change and the industrial development are high costly to convert the processing.

\subsection{Organic Synthesis}

In organic synthesis, primarily, lipases are used for catalyzing the reactions of enantioselective for fine chemicals synthesis and preparing chiral intermediates especially for pharmaceuticals [26, 27]. In therapeutics field, lipases are used in macrolide products synthesis process such as epothilones, which show the activity of potent antitumor against human tumor cell lines wide spectrum including the cell lines of multidrug resistant [28]. The introduction of chirality at position C15 in synthetic epothilone A $[29,30]$ and epothilone D [28], the most lipase enantioselective produced by Pseudomona sp. and applied in the process. Lipase from Candida rugosa catalyzes the antimicrobial compounds enzymatic resolution (R)- and (S)-elvirol and their derivatives (R)- (-) and (S)- (+) curcuphenol [31]. The Novozym 435 of lipase produced by Candida antarctica B utilized to catalyze antifungal agent rapamycin and 42001</Yeaerivatives and the immunosuppressant acylation (e.g., 42-hemiadipate, rapamycin 42-hemisuccinate) with complete regioselectivity with various acylating agent and high yields [32], lipase of psychrophiles (LipB 68) produced by Pseudomonas fluorescens B68, significantly the trensesterification catalyzing of both $\alpha$-phenylpropanol and $\alpha$-phenylethanol at $20^{\circ} \mathrm{C}$ [33]. The area where extremophiles novel lipase e.g. low temperature active enzymes for temperature sensitive-compound synthesis has a promising-potential.

\subsection{Biodesel Productions}

In biodiesel production, a mono-alkyl fatty-acid ester ( ethyl esters and preferentially methyl), has been showan evaluated like diesel replacement. A few advantages in biodiesel over diesel of petroleum; biodegradable; its combustion- products have decreased sulfur oxides, carbon oxides, and particulates levels [34]. Lipase from thermophiles, psychrophiles, and mesophiles are tested for biodiesel production including the enzymes produced by mesophile Rhizomucor miehei (ion exchange- resins immobilization) and thermophilic lipase, Thermomyces lanuginose, immobilized on the gel of silica used for sunflower oil conversion by methanolysis into biodiesel [35]. Lipases from Novozym 435 [36] and Burkholderia cepacia [37] were utilized for soybean-oil. Pseudomonas fluorescens B68 ( psychrophilic lipase) has Lip B68, which found to be efficient in biodiesel production and esterifications at $20^{\circ} \mathrm{C}$ [33]. Several processes for the production of biodiesel fuel have been developed. The transesterification utilizing alkali catalysis gives triglycerides conversion high levels in short- reaction times to methyl esters. Therefore, this process has been utilized for the production of biodiesl fuel in several countries, including United States, Italy, Germany, France, and Belgium, with exceeding 
100,000-tons yearly from fuel production [38]. Thermo- and alkalistable esterases/ lipases from alkali-thermo-philes shoud own an advantage more over from those in mesophilic microorganisms. For repeating, the keeping has to be greater-than a new industrial process development cost. The Lip A/B lipases produced by Thermosyntropha lipolytica, although elevated temperature and active alkaline $\mathrm{pH}$, there is no active significance in esterification- assay with methanol and ethanol. However, lipase of thermophile produced by Bacillus sp.J33 can catalyze methyl oleate synthesis at $60^{\circ} \mathrm{C}$., which may be used successfully for the production of biodiesel [39].

\subsection{Agrochemical Industries}

In the industry of agrochemical, lipases utilized for herbicides synthesis. A novel herbicide has been named Indofan in paddy fields utilized for grass weeds. In 1999, a racemic mixture was commercialized; however, by examining each enantiomor herbicidal activity, only the active is (S)- enantiomer. To enantiomer synthesization, lipase catalyzed-enzymatic resolution combination and the techniques of chemical inversion were used successfully [40].

\subsection{Flavor Esters Production}

Flavor esters production by plant sources extraction and fermentation is expensive, time consuming, and restricted to natural materials supply. Alternative one used for catalyze the lipases production of fragrance and flavor [41-43]. Among some lipases examples of food flavor development is Mucor miehei lipase uses to citronellol catalyze esterification and geraniol with short chain fatty-acids [44]. Pancreatic and fungal lipases were used to lipolysis reactions enhancement and odor of sharp in Idiazabal and piquant flavor development, made of cheese from milk of raw ewes, [45]. ( PERLINK Vis peppermint oil component and is industrial scale production by ( \pm )-menthol optical resolution. (ptical rel and esters of menthol are high significant from view the point of industry than $( \pm)$ - menthol. ( - menthol menthol are high significant from view the point of industry than $( \pm)$ - mentholion. Text $>[45]</$ DisplayText $\rangle\langle$ record $><$ rec-number $>307</$ rec-number $\rangle<$ for, chewing gums, toothpaste, and cosmetics. (-)-Menthol has been synthesized by $( \pm)-$ menthol enantioselective transesterification utilizing Burkholderia cepacia lipase [46].

\subsection{Food Production}

In the application of microbial lipases, they utilized for preparations of food products such as in miscellaneous processing, cosmetics, pharmaceuticals, and detergent compositions. Conequently, in food situ, eleboration of lipases by the present of microrganisms or raw materials growth used in certain foods production. The localizzation of microbial lipases production in the system of food is important for textural changes and flavor development to make food acceptable and palatable.

\subsubsection{Cheese Ripening}

According to Stadhouders, the ripening of cheese has [47], the hydeolysis during pasteurized milk ripening (Dutch cheese) is dependent largely upon production in situ of microbial lipases, as a reason that lipase of milk was more sensitive for heating than bacterial lipases, and no-lipase was detected in Dutch-rennet. Furthermore, bacterial origin lipase activity was found in young-cheese for a few days and was affectimg cheese flavour. A related work was shown by Stadhouders and Driessen [48] that Alcaligenes-viscolactis and its exo-cellular lipase, with raw milk association used for making of cheese could survive a pasteurization, the treatment of heat at $74{ }^{\circ} \mathrm{C}$ for 10 second. A heat treatment of more sever at $90{ }^{\circ} \mathrm{C}$ for 10 second. It was important that only the preparation of cheese from receiving lower heat treatment of milk was found, incubation for 6 weeks, to contain acidity normal complement. It is important, fro the cheese-flavor development stand point, that the raw milk lipase e.g. Pseudomonas fragi [49] with stood a heat treatment at 62 or $72{ }^{\circ} \mathrm{C}$ for $30 \mathrm{~min}$. The lipase complete inactivation ha s heat required at $66{ }^{\circ} \mathrm{C}$ for 1 hour and $70{ }^{\circ} \mathrm{C}$ for ten min [50, 51]. Microorgansms of lipolysis often exist in raw-milk 6-8 including Achromobacter lipids, Achromobacter lipolyticum,vPseudomonas fragi and P fluorescens. Milk pasteurization for making of cheese will not completely inactivate their respective lipases that essential to cheese flavor producing fatty acids. Swiss cheese has more free-fatty-acid (FFA) content [52] than the other most semi-hard cheese as cheddar and gouda. The highest significant different between other smi-hard and swiss cheeses is tha formation of bacterium (Propionibacterium), the former requires propionic-acid to carry on process of ripening. Oterholm, et al., have been shown these bacteria to contain lipase of intracellular, but no lipase of extracellular was found [52]. Honsono studied on lipases in cheese yeasts of limburger provided evidence for these enzymes are involved in surface ripened cheese maturation [53]. He found that Debarymyces kloeckeri and Candicla mycodema produce-lipases which were highly active at 4.5 of $\mathrm{pH}$ and presented activity at 7.0 of $\mathrm{pH}$. C.mycoderma lipase produced-different amounts of oleic, stearic, palmitoleic, palmitic, and myristic acids from fat of milk than the lipase of D.kloeckeri did. Blue veined-cheeses are depending on Penicillium 
roqueforti and connected to varieties of this-mold for flavor-development. Imamura, et al., have been isolated both endo- and exocellular from this-organism and presented them to be large resposiblly for flavor development [54]. Eitenmiller, et al., have been studied lipase of th exocellular and established that it had 8.0 of $\mathrm{pH}$ and $37{ }^{\circ} \mathrm{C}$ of optimum temperature [55]. The production of lipase was inhibited by butter oil, but a $5 \%$ emulsion of butter oil like resulted substrate in the maximum of lipolytic activity. In a rennet cheese as a cheddar, the predominant bacterial flora are lactic streptococci that added up to the milk in period of cheese making and adverntitious-lactobacilli. Oterholm, et al., have been indicated that the lactic starter bacterial culture, i.e. S.cremoris and Streptococcus lactis and the lactobacilli production of intracellar lipases and esterases. They presented that lipase is significant in cheese ripening [56].

\subsubsection{Vegetables}

Vegetables such as brussels sprout, cucumbers, cabbage, etc., could be fermented by the bacteria of lactic acid. Vorbeck, et al., presented that the FFA amount considerably increased in fermented brussels sprouts and cabbage, because the lipase activity of lactic acid bacteria one or more species [57]. The substrates of vegetable liberated lipases, which have a neutral $\mathrm{pH}$ as a optimal activity were not considered significant, due to increasing rapidly in ion concentration of hydrogen would has a limited effective to their activity. Subsequently, Pederson has marked the changes occur in all fractions of lipid during cucumbers lactic fermentation [58]. Near from four fold have been increased in FFA that occurred in forming process of pickle. Increased amounts of linolenic and linoleic-acids have been found; and, while no capric, caprylic, or caproic acids were established in fresh cucumbers, these acids may show in pickles. Fat hydrolysis basis were formed by bacterial lactic acid during the fermentation period of 22 days.

\subsubsection{Meat Production}

In an Italian method, the curing of meat product by hams preparation, dry sodium chloride is the only-chemical used in curing. Giolitti was found the fermentation of lactic had taken-place that contain increased-levels of compounds of volatile flavor including fatty acids such as mayristic, propionic, and butyric [59]. The conclusion for lipases of bacteria curing these fatty acids through the production and involved in development of flavor. Cantoni, et al., in another study observed that, during dry italian sausages ripening, Lactobacilleae and Micrococcaceae play a signifcants role in the development of flavor [60]. Certain species of Micrococcus have been especially to nonvolatile and numerous volatile fatty acids and the fat of pork were detected in ripened-sausages. Actual determinations of enzyme activity during Italian sausage ripening for more than 70 days period [61]. The activity of lipase was thought to be microbial-origin and detected during the process of ripening.

\subsubsection{Fish Process}

Lipolytic fungi used for fish processing. The apprach of resourceful to discard fat excessivly fish from menhaden was demonstrated [62]. They found 2 microorganisms, Geotrichum candidum and Candida lipolytica, reduced this fatty fish lipid content and increased significantly the final product of the protein content. Organisms of both elaborated lipases that yield may be directed by growth conditions adjustment. This approach had provided a product advantage of having an appealing and pleasant flavor charactristics.

\section{Conclusion}

In this review, Lipase and esterase are presenting highly candidate because contains of them are promising in variant felids. Also, they can be produced by bacterial and fungal production. Lipases applications and their biotechnology significant are presented in different field such as medical biotechnology, detergent industries, organic synthesis, biodiesel production, agrochemical industries, flavor industries, and food industries.

\section{Acknowledgments}

This work was financially supported by the National Natural Science Foundation of China (No. 31170078), the National High Technology Research and Development Program of China (Nos. 2011AA02A204 and 2013AA065805), the Natural Science Foundation of Hubei Province (No. 2015CFA085), and the Fundamental Research Funds for HUST (Nos. 2014NY007 and 2014QN119).

\section{References}

[1]. D. Ollis, E.C., M. Cygler, B. Dijkstra, F. Frolow, S. Franken, M. and S.J.R. Harcel, I. Silman, The hydrolase fold. Protein Eng, 1992. 5(197-211).

[2]. M. Nardini, B.W.D., Hydrolase fold enzymes: the family keeps growing. Curr Opin Struct Biol, 1999. 9(732-737).

[3]. Blow, D., More of the catalytic triad. Nature, 1990. 351(694-695).

[4]. L. Brady, A.M.B., Z.S. Derewenda, E. Dodson, G. Dodson, S. Tolley, J.P. Turkenburg, L. Christiansen, B. Huge-Jensen, L. 
Norskov, L. Thim, U. Menge, A serine protease triad forms the catalytic centre of a triacylglycerol lipase. Nature, 1990. 343(767-770).

[5]. M. Cygler, J.D.S., J.L. Sussman, M. Harel, I. Silman, M.K. Gentry, B.P. Doctor, Relationship between sequence conservation and three-dimensional structure in a large family of esterases, lipases, and related proteins. Protein Sci, 1993. 2(366-382).

[6]. F.K. Winkler, A.D.A., W. Hunziker, Structure of human pancreatic lipase. Nature, 1990. 343(771-774).

[7]. A.M. Brzozowski, U.D., Z.S. Derewenda, G.G. Dodson, D.M. Lawson, J.P. Turkenburg, F. Bjorkling, B. Huge-Jensen, S. Patkar, L. Thim, A model for interfacial activation in lipases from the structure of a fungal lipase-inhibitor complex. Nature, 1991. 351(491-49).

[8]. T. Suzuki, T.N., T. Kurihara, T. Nishino, N. Esaki, A coldactive esterase with a substrate preference for vinyl esters from a psychrotroph, Acinetobacter sp. strain no. 6: gene cloning, purifcation, and characterization. J Mol Catal B Enzym, 2002. 16(255-263).

[9]. H.E. Kim, I.S.L., J.H. Kim, K.W. Hahn, U.J. Park, H.S. Han, K.R.Park, Gene cloning, sequencing, and expression of an esterase from Acinetobacter lwoYi I6C-1. Curr. Microbiol, 2003. 46(291-295).

[10]. A. Glieder, M.P., A. Schmidt, T. Stanzer, A. Reisner, H. Schwab, Cloning, expression and characterization of a new 2-Cl-propionic acid ester hydrolase from B. subtilis. J Mol Catal B Enzym, 2002. 19-20(237-245).

[11]. J.Y. Kim, G.S.C., Y.J. Kim, Y.W. Ryu, G.J. Kim, A new isolate Bacillus stearothermophilus JY144 expressing a novel esterase with high enantioselectivity to (R)-ketoprofen ethyl ester: strain selection and gene cloning. J Mol Catal B Enzym, 2002. 18(133-145).

[12]. G.J. Kim, E.G.L., B. Gokul, M.S. Hahm, D. Prerna, G.S. Choi, Y.W. Ryu, H.-S. Ro, B.H. Chung, Identifcation, molecular cloning and expression of a new esterase from Pseudomonas sp. KCTC 10122BP with enantioselectivity towards racemic ketoprofen ethyl ester. J Mol Catal B Enzym, 2003. 22(29-35).

[13]. G.J. Kim, G.S.C., J.Y. Kim, J.B. Lee, D.H. Jo, Y.W. Ryu, Screening, production and properties of a stereospeciWc esterase from Pseudomonas sp. S34 with high selectivity to (S)-ketoprofen ethyl ester. J Mol Catal B Enzym, 2002. 17(29-38).

[14]. R.D. Schmid, R.V., Lipases: interfacial enzymes with attractive applications. Angew Chem Int Ed, 1998. 37(1608-1633).

[15]. Balca o, V.M., Paiva, A. L., Malcata, F. X, Bioreactors with immobilized lipases: State of the art. Enzyme Microb Technol, 1996. 18(392-416).

[16]. Bornscheuer, U.T., Bessler, C., Srinivas, R., Krishna, S. H, Optimizing lipases and related enzymes for efficient application. Trends Biotechnol, 2002. 20(433-437).

[17]. Jaeger, K.E., Reetz, M. T, Microbial lipases form versatile tools for biotechnology. Trends Biotechnol, 1998. 16(396-403).

[18]. Jaeger, K.E., Ransac, S., Dijkstra, B. W., Colson, C., Van Heuvel, M., Misset, O, Bacterial lipases. FEMS Microbiol. Rev, 1994. 15(29-63).

[19]. Jaeger, K.E., Dijkstra, B. W., Reetz, M. T, Bacterial biocatalysts: Molecular biology, three-dimensional structures, and biotechnological applications of lipases. Annu Rev Microbiol, 1999. 53(315-351).

[20]. Schmidt1).E., DijkstrRecombinant microbial lipases for biotechnological applications. Bioorg Med Chem, 1999. 7(2123dt1).E.

[21]. Villeneuve, P., Muderhwa, J. M., Graille, J., Haas, M. J, Customizing lipases forbiocatalysis: A survey of chemical, physical and molecular biological approaches. J Mol Catal B Enzym, 2000. 9(113-148).

[22]. Sehanputri, P.S., Hill, C. G, Biotechnology for the production of nutraceuticals enriched in conjugated linoleic acid: II. Multiresponse kinetics of the hydrolysis of corn oil by a Pseudomonas sp. lipase immobilized in a hollow-fiber reactor. Biotechnol Bioeng, 2000. 69(450nputri

[23]. Lucas, K.H., Kaplanill, C. G, BiOrlistat a novel weight loss therapy. Ann Pharmacother, 2001. 35(314s, 8).

[24]. Akimoto, T., Nagase, Y, Novel transdermal drug penetration enhancer: Synthesis and enhancing effect of alkyldisiloxane compounds containing glucopyranosyl group. J Control Release, 2003. 88(243-252).

[25]. Godfry, T., West, S, Industrial Enzymology. The Application of Enzymes in Industry. Nature Press New York, 1996.

[26]. Klibanov, A.M., Improving enzymes by using them in organic solvents. Nature, 2001. 409(241-246).

[27]. Patel, R.N., Microbial/enzymatic synthesis of chiral drug intermediates. Adv Appl Microbiol, 2000. 47(33-78).

[28]. Broadrup, R.L., Sundar, H. M., Swindell, C. S, Total synthesis of 12,13-desoxyepothilone B (Epothilone D). Bioorg Chem, 2005. 33(116drup,

[29]. Zhu, B., Panek, J. S, Total synthesis of epothilone A. Org Lett, 2000. 2(2575-2578).

[30]. Zhu, B., Panek, J. S, Methodology based on chiral silanes in the synthesis of polypropionate-derived natural products-total synthesis of epothilone A. Eur J Org Chem, 2001. 001(1701B., Pan

[31]. Ono, M., Suzuki, K., Tanikawa, S., Akita, H, First synthesis of (b)- and ( )- elvirol based on an enzymatic function. Tetrahedron Asymmetry, 2001. 12(2597M., Suz

[32]. Gu, J., Ruppen, M. E., Cai, P, Lipase-catalyzed regioselective esterification of rapamycin: Synthesis of temsirolimus (CCI-779). Org Lett, 2005. 7(3945-3948).

[33]. Luo, Y., Zheng, Y., Jiang, Z., Ma, Y., Wei, D, A novel psychrophilic lipase from Pseudomonas fluorescens with unique property in chiral resolution and biodiesel production via transesterification. Appl Microbiol Biotechnol, 2006. 73(349-355).

[34]. Iso, M., Chen, B., Eguchi, M., Kudo, T., Shrestha, S, Production of biodiesel fuel from triglycerides and alcohol using immobilized lipase. J Mol Catal B Enzym, 2001. 16(53-58).

[35]. Al.-58). Chen, Production of biodiesel by lipase-catalyzed transesterification of vegetable oils: A kinetics study. Biotechnol Prog, 2005. 21(1442-1448).

[36]. Du, W., Xu, Y. Y., Zeng, J., Liu, D. H, Novozym 435-catalysed transesterification of crude soya bean oils for biodiesel production in a solvent-free medium. Biotechnol Appl Biochem, 2004. 40(187-190).

[37]. Noureddini, H., Gao, X., Philkana, R. S, Immobilized Pseudomonas cepacia lipase for biodiesel fuel production from soybean oil. Bioresour Technol, 2005. 96(769-777).

[38]. Fukuda, H., Kondo, A., Noda, H, Biodiesel fuel production by transesterification of oils. Biosci Bioeng, 2001. 92(405-416).

[39]. Nawani, N., Dosanjh, N., Kaur, J, A novel thermostable lipase from a thermophilic Bacillus sp.: Characterization and esterification. Biotech Lett, 2004. 20(997-1000).

[40]. Tanaka, K., Yoshida, K., Sasaki, C., Osano, Y. T, Practical asymmetric synthesis of the herbicide (S)-indanofan via lipase-catalyzed kinetic resolution of a diol and stereoselective acid-catalyzed hydrolysis of a chiral epoxide. J Org Chem, 2002. 67(3131-3133)

[41]. Claon, P.A., Akoh, C. C, Enzymatic synthesis of geraniol and citronellol esters by direct esterification in n-hexane. Biotechnol Lett, 1993. 15(1211, P.A.,

[42]. Gonza P.A., Akoh, C. C, EnzymaticLipase-enhanced activity in flavour ester reactions by trapping enzyme conformers in the presence of interfaces. Biotechnol Bioeng, 1998. 59(122-127). 
[43]. Karrachaabouni, M., Pulvin, S., Touraud, D., Thomas, D, Enzymatic synthesis of geraniol esters in a solvent free system by lipases. Biotechnol Lett, 1996. 18(1083-1088).

[44]. Laboret, F., Perraud, R, Lipase-catalyzed production of short-chain acids terpenyl esters of interest to the food industry. Appl Biochem Biotechnol, 1999. 82(185ret, F

[45]. Barron, L.J., Hernandez, I., Bilbao, A., Flanagan, C. E., Najera, A. I., Virto, M., Perez- Elortondo, F. J., Albisu, M., de Renobales, $\mathrm{M}$, Changes in lipid fractions and sensory properties of Idiazabal cheese induced by lipase addition. J Dairy Res, 2004. 71(372on,

[46]. Athawale, V., Manjrekar, N., Athawale, M, Enzymatic synthesis of chiral menthyl methacrylate monomer by Pseudomonas cepacia lipase catalyzed resolution of ( )-menthol. J Mol Catal B Enzym, 2001. 16(169wale,

[47]. Stadhouders, J.J., Meded, Landbouwhogesch. Wageningen, 1956(56:67).

[48]. Driessen, F.M., J.J. Stadhouders, Melk Zuiveltijdschr. Ned, 1970. 25(141).

[49]. Nashif, S.A., F.E. Nelson, J, Dairy Sci, 1953. 36(698).

[50]. Lu, J.Y., B.J. Liska, Appl. Microbiol, 1969. 18(104).

[51]. Lu, J.Y., B.J. Liska, , Ibid, 1969. 18(108).

[52]. Oterholm, A., Z.J. Ordal, L.D. Witter, Ibid. , 1970. 53(529)

[53]. Hosono, A., Nippon Chikusan Gakkai-Ho, 1970. 41(519).

[54]. Imarnura, T., K. Kataoka, Dairy Sci. Abstr, 1967. 29(215).

[55]. Eitenmiller, R.R., J.R. Vakil, K.M. Shahani, J, Food Sci, 1970. 35(130).

[56]. Oterholm, A., Z.J. Ordal, L.D. Witter, Appl Microbiol, 1968. 16(524 ).

[57]. Vorbeck, M.L., M.N. Albury, L.R. Mattick, F.A. Lee, C.S.Pederson, J Food Sci, 1963. 28(495).

[58]. Pederson, C.S., L.R. Mattick, F.A. Lee, R.M. Butts, Appl Microbiol, 1964. 2(513).

[59]. Giolitti, G., C.A. Cantoni, M.A. Bianchi, P. Renon, J Appl Bacteriol, 1971. 34(51).

[60]. Cantoni, C.A., M.R. Molnari, P. Renon, Ibid, 1967. 30(190).

[61]. Caserio, G., C. Gervasini, Arch Vet Ital, 1969. 20(161).

[62]. Burkholder, L., P.R. Burkholder, A. Chu, N. Kostyk, O.H. Roels, Food Technol, 1968. 22(76). 